\title{
DIREITO PENAL DO INIMIGO E TERRORISMO
}

CRIMINAL LAW OF ENEMY AND TERRORISM

Felipe Rodrigues da SILVA ${ }^{1}$

Gerson Faustino ROSA ${ }^{2}$

ISSUE DOI: $10.21207 / 1983.4225 .827$

\section{RESUMO}

A Constituição Federal de 1988 fundou a República Federativa do Brasil como Estado Democrático de Direito compromissado na promoção da dignidade da pessoa humana. Nesse sentido, a dignidade humana é vetor de toda a atividade estatal, inclusive em matéria penal. Entretanto, no contexto de expansão do Direito Penal decorrente do aumento expressivo da criminalidade, exsurge o discurso do Direito Penal do inimigo, modernamente apresentado por Günther Jakobs, segundo o qual é necessário negar a condição pessoa a certos indivíduos que por seu comportamento demonstrem um afastamento permanente da ordem jurídica. A esses indivíduos, rotulados como inimigos, dispensa-se um Direito Excepcional, com características próprias de um direito de guerra cuja finalidade é eliminar um perigo do seio social. Nas recentes legislações antiterroristas pelo mundo, inclusive no Brasil através da Lei 13.260/2016, observa-se certa aproximação com a teoria do Direito Penal do inimigo, tendo em vista a adoção de mecanismos excepcionais de atuação estatal, a exemplo da ampla antecipação da intervenção penal, bem como a cominação de penas excessivamente elevadas aos que preparam ou praticam atos de terrorismo.

Palavras-chave: Dignidade Humana. Direito Penal. Inimigo. Terrorismo.

\footnotetext{
ABSTRACT

The Federal Constitution of 1988 founded the Federative Republic of Brazil as a Democratic State committed in the promotion of the dignity of human person. In this respect, human dignity is the vector of all state activity, including criminal matters. However, in the context of the Criminal Law extension

${ }^{1}$ Graduado em Direito pela Universidade Estadual de Maringá (UEM), Maringá/PR. Assessor Legislativo da Câmara Municipal da Maringá/PR.

${ }^{2}$ Professor de Direito Penal na Universidade Estadual de Maringá (UEM), Maringá/PR. Doutorando, mestre e especialista em Ciências Penais.
} 
in consequence of the expressive advancement of crime, the enemy's Criminal Law speech stands up, modernly presented by Günther Jakobs, according to which it is necessary to deny the condition of person to certain individuals that, by their conduct, demonstrate a permanent distance from the juridical order. These individuals, labeled as enemies, shall be exempt from an Exceptional Right, with its own features of a war right whose aim is to eliminate a danger from the society. In recent anti-terrorist legislations around the world, including Brazil through the 13.260/2016 Law, it is observed that some approximation to the enemy's Criminal Law theory, in view of the adoption of exceptional mecanisms of state performance, for example the broad participation of the criminal intervention, as well as threat of excessively high penalties to those who prepare or practice terrorism acts.

Keywords: Human dignity. Criminal Law. Enemy. Terrorism.

\section{INTRODUÇÃO}

O constituinte brasileiro de 1988 conferiu tratamento diferenciado ao terrorismo na ordem jurídica, na medida em que ordenou ao legislador ordinário considerá-lo como crime inafiançável e insuscetível de graça ou anistia, em verdadeira equiparação aos crimes hediondos.

Cumprindo-se o mandado constitucional de criminalização, em 16 de março de 2016 foi promulgada a Lei $\mathrm{n}^{\circ} 13.260$ que disciplinou o terrorismo no Direito brasileiro, tratando de disposições investigatórias e processuais, bem como reformulando o conceito de organização terrorista.

Todavia, a novel legislação apresenta traços que se aproximam da Teoria do Direito Penal do inimigo, eis que é possível inferir um tratamento excessivamente rigoroso com o terrorista mediante a criminalização de atos preparatórios e a cominação de penas desproporcionais.

Assim, o presente artigo objetiva verificar se as disposições da Lei n. ${ }^{\circ}$ 13.260/2016 compatibiliza-se com os princípios decorrentes da Constituição Federal que institui a República Federativa do Brasil em um Estado democrático de Direito compromissado na promoção da dignidade da pessoa humana.

Para tanto, expõe-se os limites da intervenção penal em um Estado democrático de Direito, bem como as características do chamado Direito Penal do inimigo e se esses traços podem ser identificados na Lei . $^{\circ}$ $13.260 / 2016$.

\section{LIMITES À INTERVENÇÃO PENAL NO ESTADO DEMOCRÁTICO DE DIREITO}


O Estado democrático de Direito é fruto dos movimentos políticos do final do século XIX e início do século XX, que pregava, além da necessidade de submissão do Estado às leis, o respeito à vontade popular e aos fins propostos pelos cidadãos ${ }^{3}$. Trata-se de um modelo de Estado fundado no princípio da constitucionalidade, isto é, legitimado por uma Constituição dotada de supremacia e força vinculante aos poderes que constitui, bem como no princípio democrático, segundo o qual são necessárias a participação popular nas decisões societárias e a garantia geral de vigência e eficácia de direitos fundamentais ${ }^{4}$.

Ademais, o Estado democrático de Direito possui uma dimensão antropocêntrica, pois ampara-se no valor da dignidade da pessoa humana, isto é, gravita-se num ser com dignidade, um fim e não um meio, um sujeito e não um objeto" . Nesse sentido, "o reconhecimento do homem enquanto homem implica o surgimento de um núcleo indestrutível de prerrogativas que o Estado não pode deixar de reconhecer, verdadeira esfera de ação dos indivíduos que delimita o poder estatal”.

A Constituição Federal de 1988 enuncia em seu art. $1^{\circ}$ que a República Federativa do Brasil se constitui em Estado democrático de Direito e tem como um de seus fundamentos a dignidade da pessoa humana. A previsão consta nos princípios fundamentais da República e antecede o rol de direitos e garantias individuais, servindo-lhes de fundamento ${ }^{7}$.

Portanto, a dignidade humana vincula a atividade estatal em todos os seus aspectos, mormente a atividade normativa em matéria penal. A dignidade humana impõe limites à intervenção penal, cuja inobservância implica na ilegitimidade/inconstitucionalidade do sistema normativo ${ }^{8}$.

\footnotetext{
${ }^{3}$ CARVAlHO, Gisele Mendes de; CARVAlHO, Érika Mendes de. Alguns Aspectos da Dimensão Constitucional da Dignidade da Pessoa Humana. In: Carlos Victor Nascimento dos Santos; Guilherme Scotti; Juraci Mourão Lopes Filho. (Org.). Direitos e Garantias Fundamentais III. 1 ed. Florianópolis: CONPEDI, 2017, v. III, p. 146-166.

${ }^{4}$ SILVA, José Afonso da. O Estado Democrático de Direito. Revista de Direito Administrativo, Rio de Janeiro, n. 173, p.15-34, jul. 1988.

${ }^{5}$ CANOTILHO, J. J. Gomes. Direito Constitucional e Teoria da Constituição. 6 ed. Coimbra: Almedina, 2002, p. 420.

${ }^{6}$ PRADO, Luiz Regis. Princípios da dignidade da pessoa e humanidade das penas na Constituição Federal de 1988. Disponível em: http://www.professorregisprado.com/resources/Artigos. Acesso em: 25 jul. 2018, p. 3

${ }^{7}$ CARVAlHO, Gisele Mendes de; CARVAlHO, Érika Mendes de. Alguns Aspectos da Dimensão Constitucional da Dignidade da Pessoa Humana. In: Carlos Victor Nascimento dos Santos; Guilherme Scotti; Juraci Mourão Lopes Filho. (Org.). Direitos e Garantias Fundamentais III. 1 ed. Florianópolis: CONPEDI, 2017, v. III, p. 157.

${ }^{8}$ Ibid, p. 146-166.
} 
Nesse cenário, decorre da dignidade humana as normas limitadoras ao poder punitivo estatal, a exemplo dos princípios da exclusiva proteção de bens jurídicos, legalidade, taxatividade e ofensividade.

Pelo princípio da exclusiva proteção de bens jurídicos entendese que não compete ao Direito Penal proteger valores meramente morais, éticos ou religiosos". Nas lições de Regis Prado, bem jurídico é "um ente (dado ou valor social) material ou imaterial haurido do contexto social, de titularidade individual ou metaindividual, reputado como essencial para a coexistência e o desenvolvimento do homem" ${ }^{10}$. Por essa visão, o princípio da exclusiva proteção de bens jurídicos indica que a tutela penal só é legítima quando socialmente necessária, inafastável para assegurar as condições de vida, o desenvolvimento e a paz social ${ }^{11}$.

O princípio da legalidade enuncia que nenhum fato pode ser considerado crime e nenhuma pena pode ser aplicada sem que antes da ocorrência desse fato haja uma lei definindo-o como crime e cominando-lhe a respectiva sanção ${ }^{12}$. O aludido princípio encontra-se delineado no art. $5^{\circ}$, inciso XXXIX da Constituição Federal, segundo o qual "não haverá crime sem lei anterior que o defina, nem pena sem prévia cominação legal". Nessa seara, o princípio da legalidade representa "a garantia política de que nenhuma pessoa poderá ser submetida ao poder punitivo estatal, se não com base em leis formais que sejam fruto do consenso democrático".

Ademais, do princípio da legalidade decorre a necessária taxatividade na tipificação das condutas, isto é, a imposição ao legislador de evitar o uso de expressões vagas, equívocas ou ambíguas na descrição típica, pois a vagueza e a imprecisão do tipo penal não protege o cidadão da arbitrariedade estatal ${ }^{13}$.

O Direito Penal de um Estado democrático deve fundar-se, ainda, pelo princípio da ofensividade ou lesividade, segundo o qual a tipificação de algum crime pressupõe efetivo dano a um bem jurídico penalmente tutelado ou, pelo menos, um perigo concreto, real e efetivo a esse bem ${ }^{14}$.

\footnotetext{
${ }^{9}$ BITENCOURT, Cezar Roberto. Tratado de Direito Penal. 17 ed. São Paulo: Saraiva, 2012, p. 61

${ }^{10}$ PRADO, Luiz Regis. Curso de Direito Penal Brasileiro, volume 1: parte geral, arts. $1^{o}$. a 120. 12. ed. rev. atual. e ampl. São Paulo: Editora Revista dos Tribunais, 2013, p.170.

${ }^{11}$ PRADO, Luiz Regis. Curso de Direito Penal Brasileiro, volume 1: parte geral, arts. $1^{o}$. a 120. 12. ed. rev. atual. e ampl. São Paulo: Editora Revista dos Tribunais, 2013. p. 169.

${ }^{12}$ BITENCOURT, Cezar Roberto. Tratado de Direito Penal. 17 ed. São Paulo: Saraiva, 2012, p. 49.

${ }^{13}$ Ibid., p. 49.

${ }^{14}$ Ibid., p. 59.
} 
Nas lições de Nilo Batista, o princípio da lesividade proíbe a incriminação de uma atitude interna e uma conduta que não exceda o âmbito do próprio autor. Nesse sentido, as ideias, convicções e desejos dos homens, bem como os atos preparatórios e autolesão não constituem fundamento para a tipificação penal. O referido autor ainda identifica outras duas funções do princípio da lesividade que são as proibições de se incriminar os simples estados ou condições existenciais (ou seja, repudia o Direito Penal do autor) e as condutas desviadas que não afetem qualquer bem jurí$\operatorname{dico}^{15}$.

Assim, o princípio da ofensividade limita a intervenção penal de um Estado democrático de Direito, pois "o legislador deve abster-se de tipificar como crime ações incapazes de lesar ou, no mínimo, colocar em perigo concreto o bem jurídico protegido pela norma penal"16.

\section{O DIREITO PENAL DO INIMIGO E O DIREITO PENAL DO CIDADÃO}

Durante um congresso realizado em Berlim no mês de outubro de 1999, o professor Günther Jakobs ${ }^{17}$ anunciou que nas sociedades democráticas seria imperiosa a admissão de um "Direito Penal do inimigo" ao lado de um Direito Penal do cidadão ${ }^{18}$, sendo aquele destinado aos inimigos ou não-pessoas e este aos cidadãos ou pessoas. Assim, o paradigma em torno do qual se constitui o Direito Penal do inimigo é atribuir a condição de "inimigo" a determinados indivíduos, aos quais é negada e privada a condição de pessoa, tornando-os não-pessoas ${ }^{19}$.

Todavia, como bem esclarece Luis Gracia Martín, a privação e negação da condição de pessoa a determinados indivíduos só é viável na medida em que se reconheça, como pressuposto lógico, que a qualidade de pessoa não é algo que lhe seja imanente, mas sim uma atribuição normativa, seja de caráter moral, social ou jurídico ${ }^{20}$.

\footnotetext{
${ }^{15}$ BATISTA, Nilo. Introdução Crítica ao Direito Penal Brasileiro. 11 ed. Rio de Janeiro: Revan, 2007.

${ }^{16}$ BITENCOURT, Cezar Roberto. Tratado de Direito Penal. 17 ed. São Paulo: Saraiva, 2012, p. 59

${ }^{17}$ Então professor catedrático de Direito Penal da Universidade de Bonn.

${ }^{18}$ MUÑOZ CONDE, Francisco. As origens ideológicas do Direito Penal do inimigo. Revista Brasileira de Ciências Criminais, São Paulo, v. 83, p.93-119, abr. 2010.

${ }^{19}$ GRACIA MARTÍN, Luis. O horizonte do finalismo e o direito penal do inimigo. Tradução de Luiz Regis Prado e Érika Mendes de Carvalho. São Paulo: Revista dos Tribunais, 2007, p. 132.

${ }^{20}$ Ibid., p. 133.
} 
O Direito Penal do cidadão (ou Direito Penal comum) regulamenta as infrações penais cometidas por indivíduos que, de um modo incidental e como simples expressão de abuso, violam a ordem jurídica a que se acham vinculados como cidadãos ${ }^{21}$. $\mathrm{O}$ delito do cidadão é visto como mero desgaste da comunidade ordenada e, como tal, passível de reparação. Assim, em resposta à delinquência do cidadão, o Estado coage-o a reparar o dano à vigência da norma sem perder seu status de pessoa ${ }^{22}$.

No Direito Penal comum, o autor do delito demonstra que ainda se portará como um cidadão, ou seja, oferece garantias de que se manterá fiel ao ordenamento jurídico. Nessa seara, Jakobs sustenta que, em princípio, "um ordenamento jurídico deve manter dentro do Direito também o criminoso", pois de um lado o delinquente tem o direito de reajustar-se com a sociedade e, por outro lado, tem "o dever de proceder à reparação e também os deveres têm como pressuposto a existência de personalidade" 23 .

Entretanto, há indivíduos que, ao praticar determinados fatos, revelam que seu comportamento não é de um cidadão (vocábulo tido como sinônimo de pessoa), mas sim de um inimigo inconciliável à sociedade e ao Direito, isto é, "seu comportamento já não é calculável conforme as expectativas normativas vigentes na sociedade" 24 .

Ao demonstrarem um afastamento provavelmente duradouro e decido do Direito, os inimigos não proporcionam a garantia cognitiva mínima necessária a um tratamento como pessoa, a exemplo dos delinquentes sexuais e os integrantes de organizações criminosas ou terroristas ${ }^{25}$. Por isso, a intervenção do Direito Penal do inimigo inicia-se nos atos preparatórios para a prática de uma infração penal e a pena dirige-se à segurança em relação a fatos futuros, e não a de fatos cometidos ${ }^{26}$.

A construção de Jakobs funda-se, essencialmente, no pensamento contratualista de Thomas Hobbes.

De acordo com Hobbes, a existência é o bem supremo para o homem que não está seguro no estado de natureza, mas em constante perigo. Isso porque, a natureza concebeu todos os homens igualmente, de modo

\footnotetext{
${ }^{21}$ Ibid., p. 82.

${ }^{22}$ JAKOBS, Günther. Direito penal do inimigo: noções e críticas. 2. ed. Tradução: André Luís Callegari, Nereu José Giacomolli. Porto Alegre: Livraria do Advogado, 2007, p. 32.

${ }^{23}$ JAKOBS, Günther. Direito penal do inimigo: noções e críticas. 2. ed. Tradução: André Luís Callegari, Nereu José Giacomolli. Porto Alegre: Livraria do Advogado, 2007, p. 26-27.

${ }^{24}$ GRACIA MARTÍN, Luis. O horizonte do finalismo e o direito penal do inimigo. Tradução de Luiz Regis Prado e Érika Mendes de Carvalho. São Paulo: Revista dos Tribunais, 2007, p. 82.

${ }^{25}$ JAKOBS, Günther. op. cit., p. 35.

${ }^{26}$ Ibid., p. 35-36.
} 
que todos têm direito a tudo. Nesse estado não há nada que seja injusto, pois não há lei e, por isso, cada um dos homens tem direito inclusive de exterminar o outro em prol da sua própria existência. Cada indivíduo procura realizar tudo quanto acredite ser necessário para preservar sua existência, bem como obter tudo aquilo que lhe pareça bom e útil ${ }^{27}$.

Nota-se, portanto, que no estado de natureza há um estado de guerra de todos contra todos; de ameaça e de perigo constante ${ }^{28}$. A precária situação do homem no estado de natureza inviabiliza a garantia de sua existência, na medida em que ninguém pode esperar dos outros a segurança necessária ${ }^{29}$.

Segundo Hobbes, uma das formas de o indivíduo sair desse estado de natureza é o estabelecimento de normas de paz, segundo as quais os homens chegam a um acordo constituindo a sociedade ${ }^{30}$. Para tanto, os homens devem limitar voluntariamente sua liberdade absoluta outorgandoa a um mesmo homem ou a uma assembleia de homens que, mediante plúrimos votos, reduzam as vontades de todos a uma só vontade. No lugar da vontade de todos, prevalece aquela necessária para a paz comum ${ }^{31}$. Esse pacto de submissão das vontades de todos à vontade de um só homem ou assembleia constitui o fundamento do Estado ou da sociedade civil ${ }^{32}$.

Dessas ideias, extrai-se que a razão de ser do Estado, ou seja, sua função, é justamente proporcionar aos homens a segurança necessária para garantia de sua própria existência ${ }^{33}$. $\mathrm{O}$ estado de guerra é superado mediante a dispensação de proteção e segurança pelo Estado aos seus cidadãos.

A proteção ofertada pelo Estado se dá, num primeiro momento, através da promulgação de leis civis. Isso porque essas leis declaram publicamente o que é de quem, o que é justo e injusto, o bom e o mau e o que deve ser feito e o que deve ser evitado na vida em sociedade. Assim, as leis civis limitam a liberdade natural dos homens de fazer aquilo que lhes bem aprouver conforme sua necessidade de sobrevivência ${ }^{34}$.

Para Hobbes, somente os cidadãos estariam sujeitos às leis civis, e não os inimigos, e por isso só aqueles poderiam transgredi-las (pois uma

\footnotetext{
${ }^{27}$ HOBBES, Thomas. O Leviatã. São Paulo: Martin Claire, 2009.

${ }^{28}$ GRACIA MARTÍN, Luis. op. cit., p. 102.

${ }^{29}$ HOBBES, Thomas. Do cidadão. São Paulo: Martin Claire, 2006.

${ }^{30}$ HOBBES, Thomas. O Leviatã. São Paulo: Martin Claire, 2009.

${ }^{31}$ HOBBES, Thomas. Do cidadão. São Paulo: Martin Claire, 2006.

${ }^{32}$ GRACIA MARTÍN, Luis. O horizonte do finalismo e o direito penal do inimigo. Tradução de Luiz Regis Prado e Érika Mendes de Carvalho. São Paulo: Revista dos Tribunais, 2007, p. 108.

${ }^{33}$ HOBBES, Thomas. O Leviatã. São Paulo: Martin Claire, 2009.

${ }^{34}$ HOBBES, Thomas. Do cidadão. São Paulo: Martin Claire, 2006.
} 
norma só pode ser descumprida por quem é seu destinatário). Nessa linha de pensamento, Hobbes concebe o cidadão como aquele indivíduo que, por meio da renúncia de seu direito a tudo, superou o estado de natureza e obrigou-se a prestar obediência às leis civis do Estado ${ }^{35}$. Por outro lado, os inimigos são aqueles que não aderiram ao pacto geral de obediência revelando não estarem dispostos a observar as leis civis e, por isso, nunca estiveram ou deixaram de estar sujeitos à lei ${ }^{36}$.

Assim, por negarem a submissão à lei, os inimigos negam as consequências dela decorrentes, razão pela qual estarão submetidos a castigos determinados pelo arbítrio do Estado. Ou seja, se o inimigo não se compromete com a lei, o Estado também não tem o dever de cumpri-la em favor do inimigo. Aos inimigos, dispensa-se verdadeiro direito de guerra que não encontra nenhum limite ético-jurídico ${ }^{37}$.

Com base nos postulados hobbesianos, Jakobs sustenta que a atuação da ordem jurídica em face dos inimigos não busca compensar o dano à vigência da norma (pois para eles não há assimilação da norma e da ordem, não existindo Direito ${ }^{38}$ ), mas sim eliminar um perigo proveniente dos indivíduos que negam o estado de cidadão e permanecem no estado de natureza $^{39}$. Aos inimigos, dispensa-se um direito de guerra, uma legislação de luta e de combate que se traduz num verdadeiro "não direito" 40 .

\section{A INCOMPATIBILIDADE DO DIREITO PENAL DO INIMIGO NO ESTADO DEMOCRÁTICO DE DIREITO}

Severas são as críticas formuladas em face do chamado Direito Penal do inimigo. Majoritariamente, a doutrina demonstrou objeção à proposta apresentada por Jakobs tanto no tocante às suas manifestações nas

\footnotetext{
${ }^{35}$ Ibid.

${ }^{36}$ HOBBES, Thomas. O Leviatã. São Paulo: Martin Claire, 2009.

${ }^{37}$ Ibid.

${ }^{38}$ ROSA, Gerson Faustino; LAZARETTI, Bruna Furini. Terrorismo e Direito Penal do Inimigo: uma análise crítica da lei $n^{o}$. 13.260/2016 em face dos Direitos Fundamentais. In. Mateus Eduardo Siqueira Nunes Bertoncini; Beatriz Vargas Ramos G. de Rezendo. (Org.). Criminologias e Política Criminal I. 1 ed. Florianópolis: CONPEDI, 2017, v.1, p. 169.

${ }^{39}$ HOBBES, Thomas. O Leviatã. São Paulo: M. Claret. 2009.

${ }^{40}$ ROSA, Gerson Faustino. A violação da personalidade humana pelo expansionismo penal. Revista de Direito e Liberdade, v. 15.3, p. 41, 2014.
} 
legislações como aos seus pressupostos teóricos e diretrizes político-criminais $^{41}$.

Resumidamente, o curso histórico do ideal de Direito traça-o como uma luta pela configuração de ordens sociais que possam se impor não só em virtude da mera força ou coação física de um poder superior. Nesse sentido, compreende-se que a força e a coação física não podem ser válidas em si mesmas como forma de imposição da ordem social, mas devem obedecer a certos limites. Assim, já de antemão e, por essa perspectiva, é possível concluir que "o Direito deve ser compreendido, pois, contra o exercício puro da força e da coação física de um poder superior e, portanto, como luta contra o Direito Penal do inimigo"42.

Gracia Martín elucida que na história as ordens sociais só adquirem o caráter de Direito quando sua obrigatoriedade se consolida a partir do pressuposto do reconhecimento do homem como pessoa responsável por tais ordens. Sobre tal aspecto, faz-se necessário apontar que o conceito de pessoa responsável remete-se imediatamente à dignidade do ser humano, conforme os postulados kantianos ${ }^{43}$. Nesse sentido, Immanuel Kant destaca que a "autonomia é pois o fundamento da dignidade da natureza humana e de toda a natureza racional" 4 .

Para Kant, o homem é um fim em si mesmo, isto é, algo que não pode ser licitamente usado como meio e é por essa razão que os seres humanos são denominados pessoas (ao contrário dos seres irracionais que ostentam valor relativo como meios e, por isso, são denominados coisas) ${ }^{45}$. Frisa-se, portanto, que sob a perspectiva kantiana, "aqui não se trata de nenhuma pessoa jurídica, ou seja, de nenhuma construção social e normativa, mas do homem empírico de carne e osso, que possui também uma determinada estrutura psíquica" ${ }^{46}$.

Assim, a dignidade humana não é algo que o Estado ou Direito atribui ao homem, mas algo que já lhe pertence pelo mero fato de ser pessoa humana, de modo que não lhe pode ser atribuída e tampouco retirada. Por

\footnotetext{
${ }^{41}$ GRACIA MARTÍN, Luis. O horizonte do finalismo e o direito penal do inimigo. Tradução de Luiz Regis Prado e Érika Mendes de Carvalho. São Paulo: Revista dos Tribunais, 2007, p. 140.

${ }^{42}$ Ibid., p. 152-153.

${ }^{43}$ GRACIA MARTÍN, Luis. O horizonte do finalismo e o direito penal do inimigo. Tradução de Luiz Regis Prado e Érika Mendes de Carvalho. São Paulo: Revista dos Tribunais, 2007, p. 153.

${ }^{44}$ KANT, Immanuel. Fundamentação da Metafísica dos Costumes. Disponível em: <https://ufpr.cleveron.com.br/arquivos/ET_434/kant_metafisica_costumes.pdf〉. Acesso em: 28 ago. 2018.

${ }^{45}$ Ibid., p. 68.

${ }^{46}$ GRACIA MARTÍN, Luis. op. cit., p. 153-154.
} 
isso, "mesmo o maior dos criminosos é igual em dignidade ao mais honesto dos homens" 47 .

Na visão kantiana, a dignidade humana ostenta caráter absoluto e, além disso, do fato de serem considerados fins em si mesmos, os seres humanos são objetos de respeito, na medida em que o atributo da dignidade restringe todo e qualquer arbítrio contra essa natureza ${ }^{48}$.

Portanto, digna de nota é a conclusão a que chega Luis Gracia Martín ${ }^{49}$ ao afirmar que:

[...] Se a dignidade humana tem um valor absoluto, se o exercício arbitrário da pura coação física sobre um homem desconhece sua dignidade, porque o instrumentaliza e o converte em uma coisa entre as coisas, e se o Direito Penal do inimigo não é senão um dispositivo de força e coação colocado a serviço da exclusão ou da eliminação de determinados homens, de tudo isso resulta, forçosamente, que a remissão a Kant de qualquer fundamentação históricoideológica de um Direito Penal como o do inimigo só pode ter como efeito a colocação do pensamento kantiano em uma situação de conflito insanável entre "opostos"; um conflito, porém, que Kant, da o valor absoluto que concede ao respeito da humanidade de todo ser humano, só poderia resolver logicamente mediante o sacrifício e a negação do Direito Penal do inimigo.

A Constituição de 1988 consagrou que a República Federativa Brasil constitui-se em Estado Democrático de Direito que tem como um de seus fundamentos a dignidade humana, nos termos do seu artigo $1^{\circ}$, inciso III. Todavia, é forçoso esclarecer que não se trata de criação do constituinte, mas apenas reconhecimento de que a dignidade humana é eminente, na medida em que tal atributo e o próprio conceito de pessoa são aferidos aprioristicamente ${ }^{50}$.

Ora, se a dignidade humana figura como um dos fundamentos do Estado Democrático, evidencia-se o caráter legitimador desse princípio,

\footnotetext{
${ }^{47}$ CARVAlHO, Gisele Mendes de; CARVAlHO, Érika Mendes de. Alguns Aspectos da Dimensão Constitucional da Dignidade da Pessoa Humana. In: Carlos Victor Nascimento dos Santos; Guilherme Scotti; Juraci Mourão Lopes Filho. (Org.). Direitos e Garantias Fundamentais III. 1 ed. Florianópolis: CONPEDI, 2017, v. III, p. 146-166.

${ }^{48}$ KANT, Immanuel. op. cit., p. 68-69.

${ }^{49}$ GRACIA MARTÍN, Luis. op. cit., p. 155.

${ }^{50}$ CARVAlHO, Gisele Mendes de; CARVAlHO, Érika Mendes de. Alguns Aspectos da Dimensão Constitucional da Dignidade da Pessoa Humana. In: Carlos Victor Nascimento dos Santos; Guilherme Scotti; Juraci Mourão Lopes Filho. (Org.). Direitos e Garantias Fundamentais III. 1 ed. Florianópolis: CONPEDI, 2017, v. III, p. 146-166.
} 
como "verdadeiro princípio material de justiça cuja inobservância pelo Direito positivo implica a própria negação de seu caráter de Direito"51.

Portanto, o Direito Penal do inimigo não pode ter lugar em um Estado democrático de Direito, justamente por negar a condição de pessoa aos seres humanos. Nesse sentido, só seria admissível esse suposto Direito caso respeite a dignidade do ser humana, situação em que não será Direito Penal do inimigo, mas autêntico Direito Penal, ou afronta essa dignidade, e nessa hipótese não poderá ter nenhuma legitimidade ${ }^{52}$.

\section{CARACTERES DO DIREITO PENAL DO INIMIGO NA LEI $13.260 / 2016$}

\section{$5.1 \quad$ ASPECTOS INICIAIS}

Como apontado, pelo discurso do Direito Penal do inimigo visase combater os indivíduos que demonstrem um distanciamento definitivo da ordem jurídica. Tais indivíduos, a exemplo dos integrantes de organizações terroristas, por recusarem a submissão a um estado de cidadania, não mereceriam participar dos benefícios do conceito de pessoa. Com efeito, a atuação da ordem jurídica objetiva a eliminação do perigo proveniente dos indivíduos que negam o estado de cidadão e continuam no estado de natureza.

Nesse contexto e diante da finalidade específica e diferenciada do Direito Penal do inimigo, seus princípios constitutivos e regras fundamentais destoam do Direito Penal do cidadão. Isso porque as circunstâncias fáticas e o perigo que caracterizam o inimigo reclamariam a adoção de instrumentos adequados para combatê-los até a inocuização ${ }^{53}$.

No enfrentamento dos inimigos, recorre-se a normativas jurídicopenais com características que permitem identificá-las como próprias de um Direito Penal do inimigo. Assim, no Direito Penal do inimigo flexibiliza-se o princípio da taxatividade, corolário da legalidade, por meio da

\footnotetext{
${ }^{51}$ Ibid., p. 146-166.

${ }^{52}$ GRACIA MARTÍN, Luis. O horizonte do finalismo e o direito penal do inimigo. Tradução de Luiz Regis Prado e Érika Mendes de Carvalho. São Paulo: Revista dos Tribunais, 2007, p. 155.

${ }^{53}$ GRACIA MARTÍN, Luis. O horizonte do finalismo e o direito penal do inimigo. Tradução de Luiz Regis Prado e Érika Mendes de Carvalho. São Paulo: Revista dos Tribunais, 2007, p. 87.
} 
criação de tipos penais abertos. Relativa-se, ainda, os princípios da ofensividade e lesividade através da ampla antecipação da intervenção penal. Do mesmo modo, afasta-se os princípios da proporcionalidade razoabilidade mediante a cominação de penas elevadas ${ }^{54}$.

Em obediência ao mandado de criminalização constante no art. $5^{\circ}$, inciso XLIII, foi aprovada, no de 2016, a Lei 13.260/2016 (Lei Antiterrorismo) que regulamenta o disposto no inciso XLIII do artigo $5^{\circ}$ da Constituição Federal, disciplinando o terrorismo, tratando de disposições investigatórias e processuais e reformulando o conceito de organização terrorista.

A referida legislação aproxima-se da Teoria do Direito Penal do inimigo na medida em que apresenta os caracteres próprios desse discurso. Utiliza-se amplamente tipos penais vagos, criminaliza-se banalmente atos preparatórios e, dentre outros aspectos, comina-se penas desproporcionais.

\subsection{A AMPLA ANTECIPAÇÃO DA INTERVENÇÃO PENAL}

Assim como em todo ato humano voluntário, idealiza-se o crime antes de praticá-lo. É inegável que existe um caminho que o crime percorre, desde o seu nascedouro como ideia no espírito do agente até o momento em que se consuma no ato final. A esse percurso chama-se iter criminis o qual se divide em uma fase interna (cogitação) e uma fase externa (atos preparatórios, executórios e consumação) ${ }^{55}$.

A primeira etapa é a cogitação que ocorre na mente do ser humano e é o início do movimento criminoso. Trata-se da elaboração mental do crime, cuja lei penal não pode alcançar ${ }^{56}$.

A segunda etapa consiste nos atos preparatórios que são externos ao agente. Nesse estágio, o agente criminoso passa da cogitação à ação objetiva armando-se dos instrumentos necessários à prática do fato, bem como procurando o local e o horário mais adequados para a realização do crime. Via de regra, os atos preparatórios são impuníveis, apesar de alguns autores admitirem sua punição quando os agentes são indivíduos criminalmente perigosos ${ }^{57}$.

\footnotetext{
${ }^{54}$ Ibid., p. 87-90.

55 BITENCOURT, Cezar Roberto. Tratado de Direito Penal. 17 ed. São Paulo: Saraiva, 2012, p. 522.

${ }^{56}$ BITENCOURT, Cezar Roberto. Tratado de Direito Penal. 17 ed. São Paulo: Saraiva, 2012, p. 522.

${ }^{57}$ Ibid., p. 523.
} 
A terceira etapa compreende os atos executórios que são aqueles que "se dirigem diretamente à prática do crime, isto é, à realização concreta dos elementos constitutivos do tipo penal". A partir desse momento, legitima-se a punibilidade do fato ${ }^{58}$.

Por fim, a última etapa traduz a consumação que ocorre, nos termos do artigo 14 do Código Penal brasileiro, quando no crime se reúnem todos os elementos de sua definição legal.

Nos termos do artigo $2^{\circ}$ da Lei 13.260/2016, o terrorismo consiste na prática por um ou mais indivíduos dos atos ali previstos, por razões de xenofobia, discriminação ou preconceito de raça, cor, etnia e religião, quando cometidos com a finalidade de provocar terror social ou generalizado, expondo a perigo pessoa, patrimônio, a paz pública ou a incolumidade pública. Nessa seara, $\mathrm{o} \S 1^{\circ}$ deste dispositivo legal enumera as condutas tidas como atos de terrorismo:

I - usar ou ameaçar usar, transportar, guardar, portar ou trazer consigo explosivos, gases tóxicos, venenos, conteúdos biológicos, químicos, nucleares ou outros meios capazes de causar danos ou promover destruição em massa;

II - (VETADO);

III - (VETADO);

IV - sabotar o funcionamento ou apoderar-se, com violência, grave ameaça a pessoa ou servindo-se de mecanismos cibernéticos, do controle total ou parcial, ainda que de modo temporário, de meio de comunicação ou de transporte, de portos, aeroportos, estações ferroviárias ou rodoviárias, hospitais, casas de saúde, escolas, estádios esportivos, instalações públicas ou locais onde funcionem serviços públicos essenciais, instalações de geração ou transmissão de energia, instalações militares, instalações de exploração, refino e processamento de petróleo e gás e instituições bancárias e sua rede de atendimento;

$\mathrm{V}$ - atentar contra a vida ou a integridade física de pessoa.

A nova legislação antiterrorista, em seu artigo $5^{\circ}$, criminaliza expressamente os atos preparatórios de terrorismo, ou seja, a preparação dos atos enumerados anteriormente, com os seguintes termos: "Realizar atos preparatórios de terrorismo com o propósito inequívoco de consumar tal

\footnotetext{
${ }^{58}$ Ibid., p. 523.
} 
delito". A pena cominada é a correspondente ao delito consumado, diminuída de um quarto até a metade.

$\mathrm{O}$ aludido tipo penal aproxima-se, evidentemente, da Teoria do Direito Penal do inimigo modernamente formulada por Günther Jakobs. A antecipação da punibilidade para os atos preparatórios evidencia uma política criminal de emergência que focaliza a proteção do sistema normativo, em detrimento da proteção de um bem jurídico ${ }^{59}$. Nesse contexto, importa salientar que os tipos penais que punem atos preparatórios baseiam-se em dados específicos de abandono duradouro da ordem jurídica e de ameaça permanente aos princípios basilares da sociedade ${ }^{60}$.

Já dizia Jakobs que o terrorista é o indivíduo que rechaça por princípio a legitimidade do ordenamento jurídico e, por isso, persegue a destruição dessa ordem. Assim, por razões lógicas, a reação do ordenamento jurídico frente ao terrorismo caracteriza-se pela circunstância de que não se trata, em primeiro plano, de compensação de um dano à vigência da norma, mas da eliminação de um perigo e, por isso, a pena se dirige à conservação com respeito a fatos futuros (e o que também justificaria o avanço da punibilidade para o âmbito da preparação do delito), e não à sanção de fatos já perpetrados ${ }^{61}$.

Assim, em consonância com o discurso apresentado por Jakobs, o legislador brasileiro criminalizou os atos preparatórios do terrorismo no artigo $5^{\circ}$ da Lei 13.260/2016.

O atual modelo de sociedade estrutura suas relações de produção e de convivência sobre o risco decorrente das novas tecnologias que apresentam grande potencial ofensivo, tais como produção industrial em larga escala, energia nuclear e Biotecnologia ${ }^{62}$.

Nesse contexto de risco, fala-se no princípio da precaução ${ }^{63}$.

\footnotetext{
${ }^{59}$ ROSA, Gerson Faustino; LAZARETTI, Bruna Furini. Terrorismo e Direito Penal do Inimigo: uma análise crítica da lei $n^{o}$. 13.260/2016 em face dos Direitos Fundamentais. In. Mateus Eduardo Siqueira Nunes Bertoncini; Beatriz Vargas Ramos G. de Rezendo. (Org.). Criminologias e Política Criminal I. 1 ed. Florianópolis: CONPEDI, 2017, v.1, p. 165.

${ }^{60}$ GRACIA MARTÍN, Luis. O horizonte do finalismo e o direito penal do inimigo. Tradução de Luiz Regis Prado e Érika Mendes de Carvalho. São Paulo: Revista dos Tribunais, 2007, p. 86.

${ }^{61}$ JAKOBS, Günther. Direito penal do inimigo: noções e críticas. 2. ed. Tradução: André Luís Callegari, Nereu José Giacomolli. Porto Alegre: Livraria do Advogado, 2007.

${ }^{62}$ ROSA, Gerson Faustino; LAZARETTI, Bruna Furini. op. cit., p. 165.

${ }^{63}$ Por esse postulado, amplamente consagrado no Direito Ambiental, em dadas circunstâncias fáticas, adota-se medidas anteriores à ocorrência de um dano, sobretudo quando há incerteza sobre a extensão e consequências da lesão.
} 
O princípio da precaução vem sendo aplicado ao Direito Penal mormente na criação de crimes de perigo abstrato que dispensam o resultado de perigo ou de concreta lesão ao um bem, sendo suficiente a simples prática da ação que se pressupõe perigosa ${ }^{64}$. Na lei antiterrorista brasileira, a aplicação do referido princípio é ainda mais acentuada, na medida em que já se considera perigosos e puníveis os atos preparatórios do terrorismo. Verifica-se que, em verdade, "o princípio da precaução parte de uma análise da sociedade de risco e culmina na compreensão da questão do terrorismo como uma constante ameaça ao bem-estar coletivo" ${ }^{\text {"65 }}$.

Nota-se que o legislador brasileiro optou por tipificar um crime de perigo abstrato, com a antecipação da tutela penal, com o fim último de eliminar um perigo: a existência do terrorista. Desprezou-se o princípio da ofensividade, segundo o qual a intervenção penal somente se justifica se houver efetivo e concreto ataque a um bem jurídico ${ }^{66}$, e aproximou-se da teoria do direito penal do inimigo, bem como do conceito de prevenção geral positiva sustentada por Günther Jakobs ${ }^{67}$.

Nesse contexto, a criminalização de ato preparatório não encontra guarida no sistema constitucional brasileiro, de modo que o artigo $5^{\circ}$ da Lei 13.260/2016 padece de inconstitucionalidade material.

\subsection{A DESPROPORCIONALIDADE DAS PENAS COMINADAS}

Outra característica que permite enquadrar determinada legislação no Direito Penal do inimigo seria a desproporcionalidade das penas cominadas. Isso porque, no âmbito de Direito Penal excepcional, não há a preocupação de conservação ou manutenção da ordem, mas de produzir condições capazes de eliminar os inimigos ${ }^{68}$. Nesse sentido, as penas elevadas possibilitam o afastamento duradouro do inimigo do meio social.

\footnotetext{
${ }^{64}$ BITENCOURT, Cezar Roberto. Tratado de Direito Penal. 17 ed. São Paulo: Saraiva, 2012, p. 274.

${ }^{65}$ ROSA, Gerson Faustino; LAZARETTI, Bruna Furini. op. cit., p. 165.

${ }^{66}$ BITENCOURT, Cezar Roberto. op. cit., p. 59.

${ }^{67}$ RIEGER, Renata Jardim da Cunha; CAVALHEIRO, Veridiana Rosa. Reflexões sobre a Lei Antiterrorismo (Lei n.13.260/2016). Revista Sintese Direito Penal e Processual Penal, v. 107, p. 208-230, 2018.

${ }^{68}$ GRACIA MARTÍN, Luis. O horizonte do finalismo e o direito penal do inimigo. Tradução de Luiz Regis Prado e Érika Mendes de Carvalho. São Paulo: Revista dos Tribunais, 2007, p. 88.
} 
Analisando-se a Lei 13.260/2016 é possível perceber essa característica que a aproxima do discurso proposto modernamente por Jakobs.

O princípio da proporcionalidade é importantíssimo instrumento de hermenêutica constitucional, amplamente admitido pela jurisprudência pátria e estrangeira. Por esse princípio, busca-se conter o arbítrio estatal mediante critérios para o controle de medidas restritivas de direitos fundamentais ou de outros interesses juridicamente protegidos ${ }^{69}$. De um lado, veda-se o excesso de poder e por outro lado a proteção insuficiente de direitos fundamentais (Untermassverbot) ${ }^{70}$.

Assim como em toda a ordem jurídica, na seara do Direito Penal também vige o princípio da proporcionalidade, segundo o qual, em qualquer circunstância, deve ser guardada a devida proporção entre a sanção penal e a gravidade do fato: quanto mais grave o fato, mais severa a sanção a ser aplicada ${ }^{71}$.

Nos termos do artigo $2^{\circ}$ da Lei 13.260/2016, à prática do crime de terrorismo comina-se a pena de 12 a 30 anos de reclusão, além da pena da ameaça ou violência correspondente. Assim, por exemplo, o indivíduo que, por uma das razões delineadas no "caput" do artigo $2^{\circ}$ da Lei Antiterrorismo, atentar contra a vida de pessoa, com a finalidade de provocar terror social ou generalizado, estará sujeito à pena do homicídio (artigo 121 do Código Penal) somada à pena do ato de terrorismo. Em termos matemáticos, o indivíduo estaria sujeito a uma pena mínima de 18 anos e máxima de 50 anos, caso o homicídio seja enquadrado na modalidade simples; se enquadrado na modalidade qualificada, as penas podem variar entre 24 a 60 anos reclusão.

Nota-se, portanto, que a pena de um terrorista homicida varia entre o dobro ao triplo daquela imposta a um homicida não enquadrado na lei antiterror. E para tanto, isto é, para que seja enquadrado como terrorista homicida, basta que o homicídio tenha sido causado por razões de xenofobia, discriminação ou preconceito de raça, cor, etnia e religião, com a finalidade de provocar terror social ou generalizado, expondo a perigo pessoa, patrimônio, a paz pública ou a incolumidade pública.

\footnotetext{
${ }^{69}$ SARMENTO, Daniel; SOUZA NETO, Cláudio Pereira de. Direito Constitucional: teoria, história e métodos de trabalho. 2. ed. Belo Horizonte: Fórum, 2014, p. 467.

${ }^{70}$ MENDES, Gilmar Ferreira; BRANCO, Paulo Gustavo Gonet. Curso de Direito Constitucional. 10. ed. São Paulo: Saraiva, 2015, p. 217-218.

${ }^{71}$ GOMES, Mariângela Gama de Magalhães. O Princípio da Proporcionalidade no Direito Penal. São Paulo: Editora Revista dos Tribunais, 2003.
} 
Não nos parece que os motivos e a finalidades especiais delineadas pela no artigo $2^{\circ}$ da Lei 13.260/2016 sejam suficientes e idôneos para justificar o aumento de até o triplo da pena cominada ao delito de homicídio.

Em primeiro lugar, um homicídio praticado por razões de xenofobia, preconceito ou discriminação de qualquer natureza já é tipificado pela ordem jurídica como homicídio qualificado pelo motivo torpe (artigo $121, \S 2^{\circ}$, inciso I do Código Penal Brasileiro) que, de acordo com entendimento doutrinário majoritário, é o motivo repugnante, ignóbil, vil, que causa nojo e sensação de repulsa ${ }^{72}$.

Em segundo lugar, mostra-se tarefa extremamente difícil definir o que seria "terror social ou generalizado", bem como balizar quando estaria exposto a perigo a incolumidade e a paz pública, na medida em que se tratam de expressões vagas e sem conteúdo preciso. A imprecisão das expressões acaba por dificultar a aplicação da norma e a torna um tipo penal aberto que afronta ao princípio da taxatividade - corolário do princípio da legalidade estrita - cuja relativização se harmoniza com o discurso do Direito Penal do inimigo ${ }^{73}$.

Aliás, uma incriminação vaga e indeterminada faz com que não haja lei definindo determinada conduta como delituosa, pois, em verdade, entrega-se ao arbítrio do intérprete e aplicador a identificação do fato como punível $^{74}$.

Salienta-se ainda que, no caso do terrorista homicida, a exposição de perigo a pessoa é inerente à conduta. Considerar tal circunstância para justificar o enquadramento da conduta na Lei Antiterror configura, em verdade, odioso bis in idem. Por outro lado, o patrimônio já constitui bem jurídico penalmente tutelado no Título II da Parte Especial do Código Penal brasileiro, não havendo motivos para nova tutela penal.

Outro ponto de desproporcionalidade identificado na lei antiterrorismo diz respeito a pena dos atos preparatórios de terrorismo $\left(\operatorname{artigo} 5^{\circ}\right.$ ) em relação à sanção aplicada à tentativa do crime de terrorismo propriamente dito $\left(\operatorname{artigo} 2^{\circ}\right)$.

\footnotetext{
${ }^{72}$ GRECO, Rogério. Código Penal Comentado. 11. ed. Niterói: Impetus, 2017.

${ }^{73}$ BARBOSA, Ruchester Marreiros. Lei antiterrorismo e Direito Penal do Inimigo. Disponível em: $<$ https://canalcienciascriminais.com.br/lei-antiterrorismo-e-direito-penal-do-inimigo/>. Acesso em: 03 out. 2018.

${ }^{74}$ SOUZA, Artur de Brito Gueiros; JAPIASSÚ, Carlos Eduardo Adriano. Direito Penal: Volume Único. São Paulo: Atlas, 2018.
} 
A natureza do bem tutelado, a excessiva especificidade da norma, a existência, ou não, de uma valoração quanto ao resultado da conduta, a pluralidade de interesses protegidos, o desvalor da conduta e os diferentes níveis de gravidade da ofensa a determinado bem jurídico são critérios de referência para a determinação da pena proporcional a conduta delitiva praticada $^{75}$.

Como visto, a conduta criminosa perpassa por quatro etapas em sequência: cogitação, atos preparatórios, execução e consumação. A cada etapa vencida, o bem jurídico tutelado pela norma penal é exposto mais intensamente a perigo ou a efetiva lesão. Assim, o desvalor atribuído ao ato preparatório é menor àquele atribuído ao início dos atos executórios. Desse modo, por lógica, a cada etapa vencida pelo agente criminoso, a sanção a ele aplicada deve ser mais severa. Nesse sentido, aliás, são os ensinamentos lições de Mariângela Gama de Magalhães Gomes ${ }^{76}$ :

[...] Resta claro que as margens penais devem hierarquizar-se segundo o tipo seja de lesão ou perigo, sancionando mais gravemente os delitos de lesão que os de perigo e, da mesma forma, a intensidade as lesões e dos perigos a que são expostos os bens jurídicos apresenta-se como fator determinante.

Entretanto, isso não ocorre na Lei 13.260/2016, na medida em que à conduta tipificada no artigo $5^{\circ}$ desta lei (tipo penal essencialmente de perigo abstrato) comina-se pena mais grave do que a tentativa da prática de atos de terrorismo (artigo $2^{\circ}$ da Lei 13.260/2016 na forma do artigo 14, inciso II do Código Penal) que, a depender do caso concreto, configurarse-á em delito de lesão.

Nos termos do artigo $5^{\circ}$ da Lei 13.260/2016, sanciona-se a realização dos atos preparatórios de terrorismo com a pena correspondente ao delito consumado, diminuída de um quarto até a metade. Assim, aplicandose a fração máxima de diminuição, isto é, metade, a pena aplicada aos atos preparatórios varia entre 06 (seis) a 15 (quinze) anos de reclusão. Por outro lado, aplicando-se o patamar mínimo de diminuição, isto é, um quarto, a pena em abstrato varia entre 09 (nove) a 22 (vinte e dois) anos e 06 (seis) meses.

Ocorre que se um indivíduo inicia a prática de ato terrorista, mas este não se consuma por circunstâncias alheias a sua vontade, isto é, se o

\footnotetext{
${ }^{75}$ GOMES, Mariângela Gama de Magalhães. O Princípio da Proporcionalidade no Direito Penal. São Paulo: Editora Revista dos Tribunais, 2003, p. 173.

${ }^{76}$ Idem, p. 174.
} 
crime for tentado, a pena a aplicada será menor do que aquela aplicada ao indivíduo que apenas realizou atos preparatórios do delito. Isso porque, nos termos do artigo $2^{\circ}$ da Lei 13.260/2016, pune-se a prática de ato terrorista com a pena de reclusão de 12 (doze) a 30 (trinta) anos. Assim, aplicandose o patamar máximo de diminuição previsto no artigo 14, inciso II do Código Penal, isto é, dois terços, a pena aplicada ao terrorismo tentado varia entre 04 (quatro) a 10 (dez) anos de reclusão. Entretanto, ao aplica-se o patamar mínimo de diminuição, isto é, um terço, a pena em abstrato varia entre 08 (oito) a 20 (vinte) anos de reclusão.

Destarte, verifica-se que o agente que prepara o crime é punido mais severamente do que aquele que inicia sua execução, mas não o consuma por circunstâncias alheias a vontade.

Portanto, observa-se que a Lei 13.260/2016 apresentam vícios manifestos de inconstitucionalidade substancial decorrentes do excesso de poder legislativo, na medida em que o Congresso Nacional inobservou a devida necessidade e adequação do ato legislativo produzido mediante a cominação de penas excessivamente elevadas ${ }^{77}$.

\section{CONCLUSÃO}

A República Federativa do Brasil foi constituída como um Estado Democrático de Direito compromissado com a promoção da dignidade humana. Assim, toda a ordem jurídica deve gravitar em torno da proteção e desenvolvimento dessa dignidade. Por essa razão, um Direito Penal compatível com a Constituição Federal deve orientar-se por princípios que, em última análise, limitam a atuação do Estado com o escopo de respeitar o valor supremo da dignidade humana.

A Teoria do Direito Penal do inimigo proposta por Günther Jakobs baliza-se na ideia de que seria necessário retirar a condição de pessoa de determinados indivíduos que demonstrem um afastamento duradouro da ordem jurídica e negam a condição de cidadão. A esses indivíduos, atribuise a condição de inimigo. Com efeito, a atuação do Direito Penal do inimigo frente as não-pessoas visa a eliminar o perigo representado por estas. Assim, criam-se normativas que flexibilizam os postulados constitucionais

\footnotetext{
${ }^{77}$ MENDES, Gilmar Ferreira; BRANCO, Paulo Gustavo Gonet. Curso de Direito Constitucional. 10. ed. São Paulo: Saraiva, 2015, p. 217-218.
} 
limitadores da intervenção penal, a exemplo dos princípios da taxatividade, ofensividade e proporcionalidade.

A recente Lei $n^{\circ}$ 13.260/2016 que disciplinou o terrorismo na ordem jurídica brasileira apresenta traços característicos da ideia proposta por Jakobs, de modo que é possível concluir que o legislador adotou a Teoria do Direito Penal do inimigo.

$\mathrm{O}$ artigo $2^{\circ}$ da referida lei, na tentativa de conceituar o terrorismo, acabou por criar um tipo penal extramente vago que compromete a taxatividade requerida para a incriminação de uma conduta e, consequentemente, viola o princípio da legalidade insculpido na Constituição Federal, segundo o qual não há crime sem lei anterior que o defina, nem pena sem prévia cominação legal.

Já o artigo $5^{\circ}$ da Lei 13.260/2016, ao tipificar os atos preparatórios de terrorismo, viola o princípio da ofensividade, na medida em que pune-se condutas incapazes de lesar ou ao menos expor a um perigo concreto um bem jurídico. E nesse contexto, o aludido dispositivo acaba por violar o princípio da exclusiva proteção de bens jurídicos, pois nenhum ente, dado ou valor social é lesado com a prática de atos preparatórios. Trata-se de evidente adoção do funcionalismo sistêmico proposto por Jakobs, segundo o qual a função do Direito Penal é a de tutelar a vigência da ordem jurídica.

Ademais, a Lei 13.260/2016 viola sem pudor o princípio da proporcionalidade, na medida em que se cominam penas excessivamente elevadas que não guardam a devida proporção com a gravidade do fato. Tanto é assim que a punição dos atos preparatórios de terrorismo é mais severa do que a aplicada ao agente que inicia a fase executória do crime, mas não o consuma por circunstâncias alheias a sua vontade. O objetivo a se alcançar com a cominação de penas elevadas é claro: excluir do seio social o perigo representado pelo inimigo terrorista.

Diante dessas constatações não há outra conclusão a que se chegar senão pela inconstitucionalidade material da Lei 13.260/2016.

Em que pese os argumentos e construções teóricas formulados por Jakobs, o discurso do Direito Penal do inimigo encontra obstáculo intransponível no axioma da dignidade humana, visto que esse valor é inerente a cada ser humano de modo que não se trata de algo que o Estado ou o Direito atribui ao indivíduo. Nesse contexto, a dignidade torna o ser humano como um fim em si mesmo a ponto de obstar qualquer atividade estatal no sentido de instrumentalizá-lo. 
Na medida em que o Direito Penal do inimigo pretende negar a condição de pessoa aos seres humanos, não pode ter lugar em Estado democrático de Direito tal como a República Federativa do Brasil, uma vez que esta funda-se, justamente, na dignidade da pessoa humana.

\section{REFERÊNCIAS}

BARBOSA, Ruchester Marreiros. Lei antiterrorismo e Direito Penal do Inimigo. Disponível em: <https://canalcienciascriminais.com.br/lei-antiterrorismo-e-direito-penal-do-inimigo/>. Acesso em: 03 out. 2018.

BATISTA, Nilo. Introdução Crítica ao Direito Penal Brasileiro. 11 ed. Rio de Janeiro: Revan, 2007.

BITENCOURT, Cezar Roberto. Tratado de Direito Penal. 17 ed. São Paulo: Saraiva, 2012.

CANOTILHO, J. J. Gomes. Direito Constitucional e Teoria da Constituição. 6 ed. Coimbra: Almedina, 2002.

CARVAlHO, Gisele Mendes de; CARVAlHO, Érika Mendes de. Alguns Aspectos da Dimensão Constitucional da Dignidade da Pessoa Humana. In: Carlos Victor Nascimento dos Santos; Guilherme Scotti; Juraci Mourão Lopes Filho. (Org.). Direitos e Garantias Fundamentais III. 1 ed. Florianópolis: CONPEDI, 2017, v. III, p. 146-166.

ESSADO, Tiago Cintra. Terrorismo conforme o direito norte-americano. In FERNANDES, Antonio Scarance; ZILLI, Marcos. Terrorismo e Justiça Penal: Reflexões sobre a eficiência e o garantismo. Belo Horizonte: Fórum, 2014.

GEMAQUE, Silvio César Arock. O combate ao terrorismo no direito inglês - uma visão de equilíbrio entre a repressão e os direitos fundamentais. In FERNANDES, Antonio Scarance; ZILLI, Marcos. Terrorismo e Justiça Penal: Reflexões sobre a eficiência e o garantismo. Belo Horizonte: Fórum, 2014.

GOMES, Mariângela Gama de Magalhães. O Princípio da Proporcionalidade no Direito Penal. São Paulo: Editora Revista dos Tribunais, 2003.

GRACIA MARTÍN, Luis. O horizonte do finalismo e o direito penal do inimigo. Tradução de Luiz Regis Prado e Érika Mendes de Carvalho. São Paulo: Revista dos Tribunais, 2007.

GRECO, Rogério. Código Penal Comentado. 11. ed. Niterói: Impetus, 2017.

HOBBES, Thomas. Do cidadão. São Paulo: Martin Claire, 2006.

HOBBES, Thomas. O Leviatã. São Paulo: M. Claret. 2009.

JAKOBS, Günther. Direito penal do inimigo: noções e críticas. 2. ed. Tradução: André Luís Callegari, Nereu José Giacomolli. Porto Alegre: Livraria do Advogado, 2007.

KANT, Immanuel. Fundamentação da Metafísica dos Costumes. Disponível em: <https://ufpr.cleveron.com.br/arquivos/ET_434/kant_metafisica_costumes.pdf>. Acesso em: 28 ago. 2018. 
MENDES, Gilmar Ferreira; BRANCO, Paulo Gustavo Gonet. Curso de Direito Constitucional. 10. ed. São Paulo: Saraiva, 2015, p. 217-218.

MUÑOZ CONDE, Francisco. As origens ideológicas do Direito Penal do inimigo. Revista Brasileira de Ciências Criminais, São Paulo, v. 83, p.93-119, abr. 2010.

PRADO, Luiz Regis. Curso de Direito Penal Brasileiro, volume 1: parte geral, arts. $1^{o}$. a 120. 12. ed. rev. atual. e ampl. São Paulo: Editora Revista dos Tribunais, 2013.

PRADO, Luiz Regis; CARVALHO, Érika Mendes de. Delito Político e Terrorismo: uma aproximação conceitual. Disponível em: <http://professorluizregisprado.com/Artigos/Delito\%20pol\%C3\%ADtico\%20e\%20terrorismo.pdf>. Acesso em: 01 set. 2018.

PRADO, Luiz Regis. Princípios da dignidade da pessoa e humanidade das penas na Constituição Federal de 1988. Disponível em: http://www.professorregisprado.com/resources/Artigos. Acesso em: 25 jul. 2018.

RIEGER, Renata Jardim da Cunha; CAVALHEIRO, Veridiana Rosa. Reflexões sobre a Lei Antiterrorismo (Lei n.13.260/2016). Revista Síntese Direito Penal e Processual Penal, v. 107, p. 208-230, 2018.

ROSA, Gerson Faustino. A violação da personalidade humana pelo expansionismo penal. Revista de Direito e Liberdade, v. 15.3, p. 41, 2014.

ROSA, Gerson Faustino; LAZARETTI, Bruna Furini. Terrorismo e Direito Penal do Inimigo: uma análise crítica da lei $n^{o}$. 13.260/2016 em face dos Direitos Fundamentais. In. Mateus Eduardo Siqueira Nunes Bertoncini; Beatriz Vargas Ramos G. de Rezendo. (Org.). Criminologias e Política Criminal I. 1 ed. Florianópolis: CONPEDI, 2017, v.1, p. 165.

SARMENTO, Daniel; SOUZA NETO, Cláudio Pereira de. Direito Constitucional: teoria, história e métodos de trabalho. 2. ed. Belo Horizonte: Fórum, 2014.

SILVA, José Afonso da. O Estado Democrático de Direito. Revista de Direito Administrativo, Rio de Janeiro, n. 173, p.15-34, jul. 1988.

SILVA SÁNCHEZ, Jesús-Maria. A Expansão do Direito Penal: Aspectos da política criminal nas sociedades pós-industriais. Tradução: Luiz Otavio de Oliveira Rocha. 3. ed. São Paulo: Revista dos Tribunais, 2013.

SOUZA, Artur de Brito Gueiros; JAPIASSÚ, Carlos Eduardo Adriano. Direito Penal: Volume Único. São Paulo: Atlas, 2018.

ZAFFARONI, Eugenio Raúl; Pierangeli, José Enrique. Manual de direito penal brasileiro: parte geral. São Paulo: Revista dos Tribunais, 2002.

ZAFFARONI, Eugenio Raúl. O inimigo no direito penal. Rio de Janeiro: Revan, 2007. 